\title{
Nutricionismo, postagens e celebridades: o que o oráculo nos diz para comer?
}

\author{
Nutritionism, posts and celebrities: what does the oracle tell us to eat? \\ Nutricionismo, publicaciones y celebridades: ¿qué nos dice el oráculo que \\ comamos?
}

\author{
Nathalie Fonseca Gloria ${ }^{1, a}$ \\ nut.nathalie@gmail.com | https://orcid.org/0000-0002-2386-3015 \\ Maria Cláudia da Veiga Soares Carvalho ${ }^{2, b}$ \\ mariaclaudiaveigasoares@yahoo.com.br | https://orcid.org/oooo-0oo1-8286-5689 \\ Cristiane Marques Seixas ${ }^{1, c}$ \\ cris.marques.seixas@gmail.com | https://orcid.org/oooo-0003-2630-9746 \\ Daniela Menezes Neiva Barcellos ${ }^{1, d}$ \\ daniela@neiva.com.br | https://orcid.org/oooo-0002-2038-3438
}

\footnotetext{
${ }^{1}$ Universidade do Estado do Rio de Janeiro, Instituto de Nutrição, Núcleo de Estudos sobre Cultura e Alimentação. Rio de Janeiro, RJ, Brasil.

${ }^{2}$ Universidade Federal do Rio de Janeiro, Instituto de Nutrição, Núcleo de Estudos e Ações de Educação Alimentar e Nutricional. Rio de Janeiro, RJ, Brasil.

a Mestrado em Alimentação, Nutrição e Saúde pela Universidade do Estado do Rio de Janeiro.

b Doutorado em Saúde Coletiva pela Universidade do Estado do Rio de Janeiro.

' Doutorado em Teoria Psicanalítica pela Universidade Federal do Rio de Janeiro.

d Doutorado em Ciência, área Alimentação, Nutrição e Saúde pela Universidade do Estado do Rio de Janeiro.
}

\section{RESUMO}

As novas tecnologias da informação e comunicação, aliadas às novas mídias e redes de comunicação, transformaram privacidade em objeto de consumo. O cenário comunicacional medeia o acesso a produtos e serviços digitais com novos parâmetros de hábito alimentar e estilo de vida saudáveis. A visibilidade confere prestígio às postagens no ambiente on-line, legitimando-as. O objetivo deste estudo foi mapear a representatividade de postagens de celebridades e compreender seus significados no campo da Alimentação e Nutrição. O problema central é o efeito mágico de um comportamento saudável em orientações doutrinárias sobre o comer. Analisamos imagens e textos de seis perfis de nutricionistas que se tornaram celebridades no Brasil. As postagens guiam seguidores, reproduzindo modelos de respostas rápidas que prometem a felicidade na ilusão de uma disciplina e do controle de si. As páginas operam como 'oráculos' para uma vida saudável, seguindo uma lógica de comunicação fast thinking, pouco propensa à expressão do pensamento.

Palavras-chave: Nutricionistas; Celebridades; Alimentação; Estilo de vida saudável; Tecnologias de comunicação. 


\section{ABSTRACT}

New information and communication technologies combined with new media and communication networks have made privacy an object of consumption. The communication scenario mediates access to digital products and services with new parameters of healthy eating habits and lifestyle behaviors. Visibility gives prestige to posts that move through the online environment, legitimizing them. The aim of this study was to map the representativeness of celebrity posts and understand their meanings in the field of Food and Nutrition. The central problem is the magical effect of healthy behavior in doctrinal guidelines on eating. We analyzed images and texts of six profiles of nutritionists who became celebrities in Brazil. Posts guide followers, reproducing rapid response models that promise happiness of the illusion of self-discipline and self-control. The webpages operate as 'oracles' for healthy living, following the logic of a fast thinking communication, not prone to the expression of thought.

Keywords: Nutritionists; Celebrities; Eating; Healthy lifestyle; Communication technologies.

\section{RESUMEN}

Las nuevas tecnologías de la información y la comunicación, combinadas com los nuevos medios y redes de comunicación, han convertido privacidad en objeto de consumo. El escenario comunicacional media el acceso a productos y servicios digitales com nuevos parámetros de hábitos alimentarios y estilos de vida saludables. La visibilidad otorga prestigio a las publicaciones que se mueven por el entorno online, legitimándolas. El objetivo de este estúdio fue mapear la representatividad de las publicaciones de celebridades y comprender sus significados en el campo de la Alimentación y la Nutrición. El problema central es el efecto mágico del comportamiento saludable en las pautas doctrinales sobre la alimentación. Analizamos imágenes y textos de mayor receptividad de seis perfiles de nutricionistas que se convirtieron en celebridades en Brasil. Las publicaciones guían a los seguidores en la resolución de preguntas pragmáticas, reproduciendo modelos de respuestas rápidas que prometen felicidad en la ilusión de una disciplina y un autocontrol. Las páginas operan como 'oráculos' para una vida sana, siguiendo una lógica de comunicación fast thinking, no propensa a la expresión del pensamiento.

Palabras clave: Nutricionistas; Celebridades; Alimentación; Estilo de vida saludable; Tecnologías de la comunicación.

Contribuição dos autores:

Concepção e desenho do estudo: Maria Cláudia Carvalho, Cristiane Seixas, Nathalie Fonseca Gloria e Daniela Menezes Neiva Barcellos.

Aquisição, análise ou interpretação dos dados: Nathalie Fonseca Gloria e Maria Cláudia Carvalho.

Redação do manuscrito: Nathalie Fonseca Gloria e Maria Cláudia Carvalho.

Revisão crítica do conteúdo intelectual: Maria Cláudia Carvalho, Cristiane Seixas, Nathalie Fonseca Gloria e Daniela Menezes Neiva Barcellos.

Declaração de conflito de interesses: não há.

Fontes de financiamento: não houve.

Considerações éticas: não há.

Agradecimentos/Contribuições adicionais: A todos os autores, professores e profissionais que compartilham saberes envolvidos neste estudo.

Histórico do artigo: submetido: 25 jan. 2021 | aceito: 13 abr. 2021 | publicado: 31 ago. 2021.

Apresentação anterior: O artigo é inspirado em um capítulo da dissertação de mestrado de Nathalie Fonseca Glória.

Licença CC BY-NC atribuição não comercial. Com essa licença é permitido acessar, baixar (download), copiar, imprimir, compartilhar, reutilizar e distribuir os artigos, desde que para uso não comercial e com a citação da fonte, conferindo os devidos créditos de autoria e menção à Reciis. Nesses casos, nenhuma permissão é necessária por parte dos autores ou dos editores. 


\section{INTRODUÇÃO}

O cenário comunicacional permite o acesso a vários produtos e serviços digitais com novos parâmetros de condutas de alimentação e estilo de vida saudáveis, cenário esse no qual postagens de celebridades nas redes sociais sobre assuntos cotidianos ganham visibilidade e prestígio. Nas releituras que nos atualizam sobre o mundo de conexões virtuais, alguns autores contemporâneos (SODRÉ, 2002; SIBILIA, 2008; LÉVY, 2009) dimensionam modificações importantes nas formas de interagir, perceber, pensar e contabilizar o real - o que possibilita aos usuários das redes sociais criar livremente seus perfis individualizados e interagir com os conteúdos que lhes convenham. A internet se configura como espaço de socialização e compartilhamento de conteúdo em larga escala. Os regimes de visibilidade (BRUNO, 2013) sustentam perfis de nutricionistas celebridades em redes sociais, como o Instagram, que medeiam dicas e sugestões de vida em suas experiências de ver e ser visto.

Os perfis de celebridades nutricionistas buscam nas reduções atrativas e soluções mágicas uma vida feliz com saúde perfeita. A pergunta que se impõe é se os perfis de celebridades seriam substitutos daqueles renomados sacerdotes ou mesmo das pitonisas da Grécia antiga revividos agora na mídia contemporânea. Segundo Lucena, Seixas e Ferreira (2020), o debate sobre a reputação repaginada nas mídias nos atualiza sobre um espaço 'fora do alcance' dos corpos nas novas formas de convivência afetiva virtual em grupos sociais e nos leva à crítica sobre consumos de fetiches, previsões e prescrições nutricionais flutuantes nas mídias sociais que produzem eco.

Optamos por uma comunicação instantânea própria da rede Instagram, que mobiliza usuários com largo alcance e alta periodicidade graças ao acesso ampliado dos aparelhos celulares. Segundo Bruno (2013), o emaranhado de circuitos de ativismo, vigilância e informação com uma circulação de postagens muda o cenário das condutas, das tendências e das orientações nutricionais. O consumo de dietas de sucesso e alimentos milagrosos é recheado de argumentos mobilizadores disfarçados por diversos interesses. Scrinis (2013) nos alerta sobre o paradigma que nomeou 'nutricionismo' - uma tentativa de explicar todos os problemas alimentares que reduz o alimento ao nutriente, impulsionando profundas transformações na alimentação humana.

O termo 'nutricionismo', inicialmente popularizado por Michael Pollan (2008) como um nome inventado por Gyorgy Scrinis, representa uma crítica a uma extrema valorização dos nutrientes e das recomendações que estudos experimentais atestam como verdades a serem seguidas como doutrinação do saudável. Hoje fica claro que reduzir todos os problemas alimentares invisibiliza aspectos culturais, sociais e políticos da alimentação e que o efeito da crença ideológica no poder dos nutrientes nos automatiza em um universo de 'faz de conta'.

O crescente número de postagens em diários pessoais sobre o que devemos e não devemos comer torna as celebridades alvos de pesquisa em busca de orientação para as condutas alimentares nesse emaranhado de informações que se tornou o mundo atual. A grande inserção de conteúdos audiovisuais sobre estilo de vida e alimentação saudáveis nas redes sociais mobiliza usuários e favorece um processo de celebritização de personagens no ambiente digital, ocasionando a possível ascensão do indivíduo considerado anônimo à condição de célebre.

Para Pimentel (2005), uma celebridade midiática gera padrões de reconhecimento social para o 'eu' a partir do olhar do 'outro' e vice-versa, legitimando, assim, perfis para replicar padrões de consumo alimentar e ressignificar códigos identificadores de estilos de vida consumidos como saudáveis na sociedade atual. Marshall (1997) afirma que as celebridades são a representação da individualidade na cultura contemporânea e carregam significados cheios de afetividade: a intimidade de uma celebridade 
marca os estilos de vida que despertam o interesse do público e tornam aspectos cotidianos da vida pessoal referências a serem seguidas.

No que tange ao estilo de vida saudável, levando em consideração o processo de celebritização (DRIESSENS, 2014) e sua construção, as celebridades emergem como vitrine - e foi esse aspecto o norte da nossa seleção de postagens. Para Sennett (2016), por meio das experiências de intimidade, a personalidade se desenvolve e se molda na confiança, no afeto e numa espécie de conforto para os usuários. Conforme descrito adiante, as citações de nutricionistas em revistas destinadas às camadas médias da população nos levaram às Redes Sociais On-line (RSO) dessas celebridades, confirmando o individualismo que já esperávamos nesse consumo de privacidades milimetricamente construídas.

Os novos heróis da cultura de consumo, em vez de adotarem um estilo de vida de maneira irrefletida, perante a tradição ou o hábito, transformam o estilo num projeto de vida e manifestam sua individualidade e senso de estilo na especificidade do consumo de bens, roupas, práticas, experiências, aparências e disposições corporais destinadas a compor um estilo de vida. (FEATHERSTONE, 1995, p. 122)

A representatividade de um recorte empírico de postagens multifacetadas, efêmeras, mutáveis, interativas e replicáveis delineou um microcosmo amostral referenciado em conceitos clássicos oriundos das Ciências Humanas. Já impregnados pela vivência e formação no campo da Nutrição, buscamos (re) orientar o olhar da pesquisa com uma análise reflexiva calcada nas Ciências Humanas, com o intuito de problematizar o aspecto 'revelação' dessas postagens. A aproximação com sacerdotisas gregas é uma metáfora crítica sobre o papel das celebridades e das dicas. Se deslocados de um mundo de divindades para a contemporaneidade, expõem efeitos de um segmento sem razão ou reflexão. Nessa crítica, a previsibilidade das orientações nutricionais de celebridades, se comparada a um espaço revelador de oráculo, evidenciaria uma redução de temáticas complexas da alimentação aos signos mágicos que operam a manutenção de nichos de um mercado consumidor midiático. Nesse sentido, poderiam ser, infelizmente, a previsão de futuro consumerista.

\section{AS REPRESENTAÇÕES SOCIAIS FLUTUANTES E AS CELEBRIDADES DAS REDES SOCIAIS}

No século XX, a privacidade tornou-se um bem de consumo que dá acesso a quase todos os produtos e serviços digitais. Alimentos da vida íntima de celebridades caem em um fosso do senso comum e se transformam em variados fetiches (LUCENA; SEIXAS; FERREIRA, 2020), que passam a ser consumidos como algo natural, em um modo de compartilhar o modus vivendi para todos os gostos, sempre acompanhado de tendências de consumo. $\mathrm{O}$ ir e vir de histórias e narrativas converge numa rede de conteúdos midiáticos (JENKINS, 2006; SCOLARI, 2013) e repercute apetites e resistências para novos consumos de artefatos culturais de vida saudável. O que Sennett (2006) denomina como "conceito meritocrático de talento e uma individualidade idealizada" (p. 161) faz convergirem os valores de mudanças individualizadas em direção contrária ao consenso e às relações solidárias para o coletivo.

A estratégia metodológica desenvolvida para análise das postagens de que trata este artigo alia estudos de Nutrição aos dos campos das Ciências Sociais e Humanas, tentando escapar das perspectivas da hegemonia biomédica do campo da Alimentação e Nutrição. Como expôs Marteleto (2010, p. 39),

[...] para realizar um investimento sustentado das questões da informação pelo ângulo das redes sociais, é relevante que as pesquisas realizadas em Ciência da Informação no Brasil atentem para o necessário aprofundamento teórico, metodológico e aplicativo. Também precisam levar em conta as possibilidades interdisciplinares e combinações metodológicas que as perguntas sobre informação e redes sociais demandam nos tempos de hoje e de sempre. 
Serge Moscovici (2009) fala em representações sociais flutuantes no coletivo, expressão que modificamos e adaptamos para auxiliar na análise das postagens em redes sociais. Para Stasiak (2009), a expansão do espaço on-line das RSO marca um processo comunicacional com relações efêmeras e transitórias que modificam as relações de tempo e espaço e que não se esgotam mais, operando com contornos não mais atrelados a uma área física nem à divisão cronológica de tempo. Nesse sentido, assumimos que as hashtags, a cerquilha, são um sinal gráfico que marca representações flutuantes no processo comunicacional e que indexam assuntos e discussões nas RSO.

As hashtags introduzem termos, escritos sem espaço, numa linguagem própria da internet. Têm a propriedade de dispor em índices os conteúdos e as discussões, ordenando esse corpus de modo a facilitar a recuperação em hiperlinks. A teoria das representações sociais emerge como elemento de sustentação para a análise de imagens e textos da vida cotidiana de usuários de RSO que seguem os perfis dessas celebridades. O ambiente digital considerou as hashtags um elemento de construção de uma linguagem de arquitetura aberta.

Para Zovin (2010), as celebridades são seletos indivíduos que promovem a vinculação de grupos sociais em função da imagem que sustentam; desse modo, na condição de experts, aliados aos avanços tecnológicos do mundo digital, os profissionais de saúde vêm construindo personagens autobiográficos com o objetivo de alcançar visibilidade e as hashtags se sobressaem na busca ativa num catálogo de ideias comuns nos discursos analisados.

\section{\#HASHTAGS: UM CONSENSO DE SIGNIFICAÇÃO}

Hashtag é o nome que dá realce aos significados marcados pelo sinal gráfico '\#’ que precede palavras escolhidas pelo usuário e aos hiperlinks gerados. As hashtags classificam e dão reconhecimento às representações do senso comum: um código de reconhecimento social de elementos que se constituem como realidade comum aos envolvidos no processo comunicacional. A partir da interação entre usuários das redes, no decurso da comunicação e cooperação, a hashtag viabiliza a comunicação, reforçando ideias comuns que advêm tanto das informações científicas quanto da ideologia cultural e da experiência prática dos sujeitos.

Por outro lado, a alimentação saudável guarda em si uma polissemia, produz na comunicação uma função de 'omnibus' de significados, nos termos de Bourdieu (1997). Essa comunicação transporta conteúdos de 'variedades', sem compromisso de vínculo, se presta ao consumo diverso, carregando tanto desigualdades sociais como bandeiras de um mundo mais justo. A polissemia do termo 'alimentação saudável', assim como 'qualidade' e 'estilo de vida', estrutura a diversidade cultural no campo da Alimentação e Nutrição (BARCELLOS, 2016; GARCIA, 1997; SILVA, RECINE, QUEIROZ, 2002).

Segundo Barcellos, o consumo de alimentação saudável em seu uso globalizado emerge como distinção social, motivando práticas de consumo capazes de se adequar aos discursos de variados veículos midiáticos - televisão, revista e rádio -, bricolando (CARVALHO, 2013) significados de comidas, utensílios e equipamentos nas práticas culinárias para todos os gostos, como marcadores de distinção social. "No universo da cidade, as expressões 'alimentação saudável' e 'qualidade de vida' transitam entre os mais diversos grupos e inspiram múltiplas leituras a partir dos contextos sociais, valores e visões de mundo de cada indivíduo" (BARCELLOS, 2016, p. 139).

Partimos da premissa de que a concepção de alimentação saudável é uma bricolagem alimentar, termo cunhado por Maria Cláudia Carvalho (2013) como uma reconstrução do conceito de Lévi-Strauss no campo da alimentação. Nesse sentido, segundo a autora, a "[...] bricolagem alimentar foi uma estratégia que atravessou as práticas de alimentação [...] como um modo de 'arrumar' o universo simbólico, uma estratégia de organização dos significados dos alimentos na vida das pessoas" (CARVALHO, 2013, p. 17). 
Assim, opera consensos cotidianos sobre os significados da 'melhor alimentação' e, nessa condição de construção temporária, adéqua-se às páginas estetizadas das celebridades. A naturalidade no consumo do saudável faz parte de esquemas de percepção e de apreciação por meio dos quais as representações sociais flutuantes nos textos foram apreendidas.

\section{SELEÇÃO DE PERFIS DE NUTRICIONISTAS/CELEBRIDADES PARA O ESTUDO}

O perfil apresenta o modo como um usuário se coloca na rede social, ou seja, como ele expõe o seu personagem autobiográfico, embora esteja ligado à ideia de personagem.

Selecionamos, aleatoriamente, os perfis analisados em revistas de extratos de camadas médias da população, que capturavam um público ledor de variedades relacionadas à alimentação, à dieta e à saúde para mapear quem são esses nutricionistas celebridades mais citados. Surgiram de páginas das revistas Boa Forma, Glamour, Bolsa de Mulher e Specialità Fitness, respectivamente, nas matérias: 'As nutricionistas fitness para seguir no Instagram' (ACHÔA, 2014), '10 nutricionistas in-crí-veis para você seguir no Insta' (10 NUTRICIONISTAS..., 2014), 'Receitas fit: 8 perfis de nutricionistas no Instagram que indicam' (FEITEIRO, 2015?) e '10 nutricionistas que você precisa seguir no Instagram' (FITNESSNUTRICAOBLOG, 2016). Na intenção de compreender as relações alimentares da sociedade atual, buscamos identificar os perfis de nutricionistas com grande visibilidade em redes sociais no contexto brasileiro. Os nutricionistas celebridades deste estudo usavam páginas abertas do Instagram e tinham número de seguidores superior a cem mil, no momento da análise.

Os oito perfis selecionados apresentavam conteúdos em destaque relacionados à alimentação saudável. Entre os perfis, somente seis foram objeto de análise, por atuarem no campo da Alimentação e Nutrição como nutricionistas graduados. Foram, portanto, excluídos os perfis associados aos profissionais de outras áreas de conhecimento, como os da Educação Física e da Biomedicina.

As páginas selecionadas - @danielcady, @aleluglio, @andreasantarosagarcia, @fernandascheernutri, @ nutricionistarodolfoperes, @patriciadavidson.nutri - foram acompanhadas durante o período de um mês. Contabilizaram-se números de curtidas e foram registrados legendas e comentários de cada publicação no período. As imagens e publicações foram sistematizadas quantitativamente, em ordem de grandeza, antes da análise de discurso.

Os dados quantitativos sobre as postagens foram ordenados por perfil de nutricionista celebridade e contribuíram para dimensionar, na página de cada um, e na observação do conjunto, o retorno (feedback) dado às postagens. As imagens que tiveram mais repercussão foram analisadas no contexto social, baseandose no referencial teórico das representações sociais flutuantes, como também nos limites da ferramenta tecnológica como forma de captura de representatividade em condições habituais de comunicação.

\section{\#Personagens semificcionais de autopromoção}

As páginas engendram os personagens autobiográficos através da narrativa imagética que promove a celebridade. A edição dos perfis envolve recursos disponíveis na internet para cuidar de detalhes com foco nas tendências e modas. Essa habilidade coloca a imagem em um jogo de cena que requer reconhecimento de elementos simbólicos por parte da audiência, caso contrário não haveria contato com os seguidores. Quantos de nós ainda nos envolvemos neste jogo de narrativas imagéticas sem perceber a violência simbólica ostentada entre sorrisos e sucessos produzidos no espaço midiático? Segundo as reflexões de Pierre Bourdieu (2006), entendemos violência simbólica como "[...] a forma branda e enrustida assumida pela violência quando esta não pode manifestar-se abertamente" (p. 213). 
A ressignificação de elementos banais da esfera íntima e privada das celebridades no espaço midiático responde a um interesse culturalmente marcado por bisbilhotices. Publicizar aspectos da intimidade das celebridades ocupa o tempo sem consequências com futilidades e velhas fantasias. As conexões das celebridades com outros personagens famosos capitalizam a imagem com narrativas e não passam despercebidas na rede. Checar conexões entre as páginas de celebridades é uma das principais atividades dos usuários do Instagram. Vínculos com celebridades de outros campos sociais - familiar ou profissional - são exaltados nas publicações.

Driessens (2014) destaca que o efeito de midiatização, catalizador de 'audiência', nas personalidades midiáticas funciona como prática de consumo de marcas e produtos. As celebridades capturam esses significados reorientando-os como uma promessa de sucesso para um clube de seguidores. Conteúdos de dicas de alimentos e dietas para adequar o corpo a um padrão fitness, assim como aqueles que reforçam laços afetivos de uma família feliz, sobressaíram-se nas postagens por convergirem na busca por um estilo de vida saudável.

\section{\#Dicas}

A dica é uma representação social impulsionada pelo conhecimento de todos que partilham o fetiche de um objeto ou ação que opera como solução de um problema. Algumas categorias de postagens - por exemplo, \#santadica - marcavam o espaço de modelos resolutivos que se repetiam ao longo do tempo. As dicas eram legitimadas por conhecimentos acadêmicos, associadas a um conselho. Geralmente assumem a disposição de um ato altruísta de quem compartilha pequenos segredos com seus seguidores como se fossem amigos.

Embora as dicas estivessem apresentadas de modo caótico, orientavam-se por uma conduta disciplinada que reproduzia um tom imperativo de saúde. Uma saúde que fazia referência à beleza e aos detalhes 'gourmetizadores' como uma distinção social - por exemplo, \#lindodemais -, em legendas de fotografias das celebridades praticando atividade física ou em momentos de lazer.

A promessa de uma revelação está muito presente, marca uma disposição e opera como 'oráculo' de orientações sobre uma vida saudável ordenadas na sequência das imagens das telas que mostram histórias de sucesso à medida que vão atualizando as informações cotidianas: nada pode dar errado, nada deve ser problematizado, como se fosse somente uma questão de aceitação: "Pelo emagrecimento rápido, sem dieta... Eu voto sim!”. Para Bourdieu (1997, p. 49), os conteúdos se atualizam em um tipo de comunicação fast thinking que não viabiliza o tempo necessário à expressão do pensamento, tal qual a alimentação fastfood, que atropela o tempo inerente ao alimentar-se.

Quando emitimos uma ideia feita é como se isso estivesse dado; o problema está resolvido. A comunicação é instantânea porque, em certo sentido, ela não existe. Ou é apenas aparente. A troca de lugares-comuns que desempenham é uma comunicação sem outro conteúdo que não o fato mesmo da comunicação. (BOURDIEU, 1997, p. 49)

Segundo Primo (2009), a vida comum, com compartilhamento de intimidades por parte desses personagens, cria vínculos afetivos estratégicos que ampliam a idolatria por parte de seus seguidores. Pena (2002) fala que o comum se torna algo especial no palco contemporâneo, numa versão espetacular da vida. As despretensiosas dicas assumem um fantástico poder terapêutico de revelação de uma evidência já experimentada, afirmando que uma alimentação saudável é capaz de curar males tal qual um remédio milagroso. 


\section{\#Fitfamily}

O nome fitfamily representa na junção das palavras fit, termo popular que faz referência aos comportamentos relacionados ao saudável, e family, família em inglês, uma estética na propensão do ser humano a 'fazer patotas', com ou sem um laço consanguíneo, mas que se unem a partir da disposição de um corpo 'fit'. A estética de corpos jovens e atléticos ostentando pouca gordura corporal e farta musculatura combina com a proposta de controle saudável de excessos e disciplina, tanto para se alimentar quanto para se exercitar - \#sportlove.

O Guia alimentar para a população brasileira (BRASIL, 2014) é uma estratégia para implementação da diretriz de promoção da alimentação adequada e saudável que integra a Política Nacional de Alimentação e Nutrição (BRASIL, 2013). Em estudo sobre os guias alimentares, Menezes e colaboradores (2015) ressaltam três virtudes para que se cumpram as inúmeras regras de alimentação saudável: ser prudente; ser moderado; ser forte. Para Santaella (2003, p. 60), as celebridades atuam como "[...] miragens de um ideal corporal a ser atingido". Sob essa ótica, o ideal corporal apresenta forte associação com um padrão de alimentação saudável como representação de estilo de vida.

A ideia de família insere elementos de amor, carinho e afeto ao incluir o seguidor no clube da celebridade. As imagens nos interiores das casas, as rotinas dos familiares, amigos, com seus animais de estimação, as fotos dos momentos de lazer são fragmentos afetuosos de memórias de um modo de viver que proporciona uma sensação de inclusão com o compromisso de proximidade. São reveladas fontes de 'alimento-prevenção' e 'alimento-cura' para os seguidores, o que nas reflexões de Angelis (2001, p. 270), serviria para “[...] proteger os indivíduos contra os riscos por agressões genéticas e do meio ambiente, incluindo os hábitos alimentares, reduzindo riscos que poderiam ser minimizados ou protelados através de uma nutrição preventiva, iniciada logo após o desmame e continuada ao longo de toda a vida.”

Uma fitfamily opera como um agente treinador de comportamento (coach) e de estilo de vida saudável, com a hashtag "\#meinspira”, apresentando nas imagens textos de ajuda e autoajuda. Os registros de comidas e de receitas, os restaurantes, as viagens, as paisagens, as mensagens motivacionais revelam uma forma de viver maternal com publicações de intimidade no contexto familiar, na companhia de filhos e marido, com a exposição do interior da casa com locais nomeados de \#teamopai, \#aniversario. A reprodução no consumo de bens prestigiosos é um modo de expressar gostos e valores de um estilo de vida que segue representações do senso comum nas hashtags \#sonho e \#paris, segundo Featherstone (1995), numa consciência de si estilizada, de acordo com parâmetros individualizados.

$\mathrm{O}$ estilo de vida insere uma conformidade àqueles que o adotam, através de modelos de vestimenta, modos de agir, opinar e falar - elementos estes que configuram um estilo de vida midiatizado, \#lifestyle. Silverstone (2002, p. 150) sinaliza a importância do papel da mídia no consumo: "Consumimos a mídia. Consumimos pela mídia. Aprendemos como e o que consumir pela mídia. Somos persuadidos a consumir pela mídia. A mídia, não é exagero dizer, nos consome”.

O compartilhamento da rotina alimentar em meio digital parece ser uma saída tanto para evitar a solidão à mesa quanto para se apropriar de valores sociais que estão associados às práticas alimentares, em hashtags como: \#quemamacuida, \#quemamaadota, \#muitoamorenvolvido.

A visibilidade de imagens com a hashtag \# comidadeverdade esteve associada a um alimento reconhecido e familiar. Uma comida do dia a dia compartilhada pelo grupo, apesar de todos os percalços e correrias da vida atual. Os pratos regionais se mostraram 'comida familiar' que confere capital através de suas características simples, de fácil identificação de um grupo - por exemplo: \#comidanordestina, \#mungunzá e \#comidacaseira. Foi explorada a tendência de um movimento brasileiro nessa ocasião, denominado 'comida de verdade', com a hashtag \#comidadeverdade, divulgado amplamente pelo Conselho Nacional 
de Segurança Alimentar e Nutricional (Consea) e pela Associação de Nutrição do Estado do Rio de Janeiro (Anerj). A 'comida de verdade' é exibida como aquela que se obtém de propriedades funcionais, da grande densidade de nutrientes e cores e revela-se capaz de fornecer energia através da degustação de algo saboroso, mesmo que não gourmetizado.

O seguidor aparece como confidente, autorizado a receber as informações, em uma posição de testemunha da vida desses nutricionistas. Fotografias apresentadas com ausência de tratamento estético prometem ser fiéis à realidade, sem maquiagens, \#semfiltro, \#proteção. Nessa perspectiva, as representações emergem como fio condutor da construção de laços que amplificam a relação celebridade-fã nas RSO, o que parece justificar que, em meio às diversas fotografias com estética colorida, a imagem monocromática fora desse padrão foi a que apresentou maior aceitabilidade pela familiaridade que a associa a um gosto pessoal da celebridade.

O discurso da felicidade se associa à construção de uma vida perfeita. O modelo de vida ostentado é o citadino, profissional de sucesso, refletido nos padrões de consumo como símbolo importante de uma vida feliz. Segundo Berlanga, García e Victoria (2013), as celebridades compartilham imagens de seus casamentos sólidos, da ausência de doenças e de comportamentos altruístas, filantrópicos e caridosos, capazes de seduzir, agradar, comover e interessar com a intenção de persuadir.

Desse modo, é o sentimento de 'espiar e consumir a vida alheia' que orienta a edição das imagens em busca de familiaridade. Na condição ilusória e superficial de uma ética do cuidado e do bem, ecológica e sustentável, \#umapaz e \#gratidao se atrapalham nas narrativas fast thinking. A preferência por variedade de propostas se engaja na estética do alimento gourmetizado, in natura.

\section{CONSIDERAÇÕES FINAIS}

As páginas dos nutricionistas celebridades se apresentam como vitrines virtuais que prometem aos seguidores um modo fantástico de ser saudável: privacidade editada ao sabor de tendências de consumo. Os conteúdos são parte de um repositório vivo de distinção social refinado e dirigido aos seguidores. Refletem e ao mesmo tempo produzem novos apetites de um saudável reducionista, sem densidade. Padroniza o 'como' ser saudável sem deixar dúvidas: o padrão de saudável não somente é possível a todos como é responsabilidade individual de cada seguidor.

Fazer parte das redes de celebridades é uma marca de prestígio e notoriedade para seus seguidores, reafirmando que a condição de popularidade é o que importa. A visibilidade e a autopromoção podem levar pessoas comuns a se tornarem celebridades, e o compartilhamento de pequenos segredos revelados, do conselho ofertado, sela essa cumplicidade entre os 'amigos'.

As representações sociais em torno da alimentação saudável ecoam tendências de consumo de modelos idealizados de uma saúde perfeita e de vida feliz caricaturais. Na análise das postagens, conteúdos de dicas de alimentos e dietas adéquam o corpo a um padrão fitness, como aqueles que reforçam laços afetivos de fitfamily feliz e compõem as narrativas desse estilo de vida saudável.

Os significados de alimentação saudável se prestam a bricolagens em moldes total flex, direcionando olhares para entretenimentos ligeiros. A ressignificação de elementos banais da esfera íntima e privada alimenta o interesse por bisbilhotices que conferem visibilidade ao padrão híbrido de saudável. O 'espiar e consumir a vida alheia' em um estilo elegante reafirma a posição de destaque no ranking e atualiza de modo feroz as práticas do nutricionismo.

As dicas sobre uma vida saudável são informações cotidianas despretensiosas, mas com uma convicção de que nada pode dar errado, nem sequer ser problematizado. Os conteúdos giram em torno de variedades rapidamente reconhecidas de elementos midiáticos e se atualizam em um tipo de comunicação fast thinking 
não propensa à expressão do pensamento, que, embora despretensiosa, é sistematicamente organizada com um olhar vigilante e atualizado sobre as tendências da moda e as novas fórmulas 'bem-sucedidas' do comer.

A presença alegre de jovens sorridentes é unânime nas publicações. O silêncio em relação ao sofrimento produzido por uma estrutura social segregadora esconde mecanismos invisíveis de violência simbólica (BOURDIEU, 2006). A construção de um padrão de vida saudável perfeita hipervaloriza uma ordem simbólica que naturaliza uma desigualdade perversa. A ilusão de chaves da felicidade obscurece o esforço de luta por políticas públicas de alimentação e o faz com a tácita cumplicidade dos seguidores, que tanto sofrem violência simbólica como a exercem de modo não intencional e não consciente.

A manutenção de um status quo de distinções sociais de um saudável estilizado baseado no Guia alimentar para a população brasileira evidencia que boa parte da população brasileira não tem condições mínimas de praticar o que se estabelece por alimentação saudável. A despolitização das postagens das celebridades reduz a potência do ser humano para implementar mudanças sociais capazes de promover uma alimentação saudável realmente para todos.

\section{REFERÊNCIAS}

10 NUTRICIONISTAS IN-CRÍ-VEIS PARA VOCÊ SEGUIR NO INSTA. Glamour, [S. I.], 2014. Disponível em: https://revistaglamour.globo.com/Beleza/Fitness-e-dieta/fotos/2014/05/10-nutricionistas-cri-veis-para-voceseguir-no-insta.html Acesso em: 05 jul. 2021.

ACHÔA, Yara. As nutricionistas fitness para seguir no Instagram. Boa Forma, [S. I.], 2 nov. 2014. Dieta. Disponível em: https://boaforma.abril.com.br/alimentacao/dieta/as-nutricionistas-fitness-para-seguir-noinstagram/. Acesso em: 05 jul. 2021.

ANGELIS, Rebeca Carlota de. Novos conceitos em nutrição: reflexões a respeito do elo dieta e saúde. Arquivos de Gastroenterologia, São Paulo, v. 38, n. 4, p. 269-271, 2001. DOI: https://doi. org/10.1590/S0004-28032001000400010. Disponível em: https://www.scielo.br/scielo.php?pid=S0004$28032001000400010 \&$ script=sci_abstract\&tlng=pt. Acesso em: 11 jan. 2021.

BARCELLOS, Daniela Menezes Neiva. Alimentação saudável e qualidade de vida na cidade: um estudo dos imaginários nas mídias. 2016. 152 f. Tese (Doutorado em Alimentação, Nutrição e Saúde) - Instituto de Saúde, Universidade do Estado do Rio de Janeiro, Rio de Janeiro, 2016.

BERLANGA, Inmaculada; GARCÍA, Francisco; VICTORIA, Juan S. Ethos, pathos y logos en Facebook. EI usuario de redes: nuevo 'rétor' delsiglo XXI. Comunicar, v. 21, n. 41, p. 127-135, 2013. DOI: http://dx.doi. org/10.3916/C41-2013-12. Disponível em: https://www.revistacomunicar.com/pdf/comunicar41-en.pdf. Acesso em: 11 jan. 2021.

BOURDIEU, Pierre. Sobre a televisão: seguido de A influência do jornalismo e Os Jogos Olímpicos. Rio de Janeiro: Jorge Zahar, 1997.

BOURDIEU, Pierre. A produção da crença: contribuição para uma economia dos bens simbólicos. Porto Alegre: Zouk, 2006.

BRASIL. Ministério da Saúde. Secretaria de Atenção à Saúde. Guia alimentar para a população brasileira. 2. ed. Brasília, DF: Ministério da Saúde, 2014. Disponível em: https://bvsms.saude.gov.br/bvs/publicacoes/ guia_alimentar_populacao_brasileira_2ed.pdf. Acesso em: 8 jun. 2021.

BRASIL. Ministério da Saúde. Secretaria de Atenção à Saúde. Política Nacional de Alimentação e Nutrição. Brasília, DF: Ministério da Saúde, 2013. Disponível em: https://bvsms.saude.gov.br/bvs/publicacoes/politica nacional_alimentacao_nutricao.pdf. Acesso em: 8 jun. 2021.

BRUNO, Fernanda. Máquinas de ver e modos de ser: vigilância, tecnologia e subjetividade. Porto Alegre: Sulina, 2013.

CARVALHO, Maria Cláudia da Veiga Soares. Bricolagem alimentar nos estilos naturais. Rio de Janeiro: Ed UERJ, 2013. 
DRIESSENS, Olivier. A celebritização da sociedade e da cultura: entendendo a dinâmica estrutural da cultura da celebridade. Ciberlegenda, Niterói, n. 31, p. 8-25, 2014. Disponível em: https://periodicos.uff.br/ ciberlegenda/article/view/36959/21534. Acesso em: 12 jan. 2021.

FEATHERSTONE, Mike. Cultura de consumo e pós-modernismo. São Paulo: Studio Nobel, 1995.

FEITEIRO, Marianna. Receitas fit: 8 perfis de nutricionistas no Instagram que indicam. Vix, [S. I.], [2015?]. Disponível em: https://www.vix.com/pt/bdm/corpo/receitas-fit-8-perfis-de-nutricionistas-no-instagram-queindicam Acesso em: 05 jul. 2021.

FITNESSNUTRICAOBLOG. 10 nutricionistas que você precisa seguir no Instagram. In: FITNESSNUTRICAOBLOG. Nutrifitness Blog, [S. I.], 11 jan. 2016. Disponível em: https:// fitnessenutricaoblog.wordpress.com/2016/01/11/10-nutricionistas-que-voce-precisa-seguir-no-instagram/ Acesso em: 5 jul. 2021.

GARCIA, Rosa Wanda Diez. Representações sociais da alimentação e saúde e suas repercussões no comportamento alimentar. Physis: Revista de Saúde Coletiva, v. 7, n. 2, p. 51-68, 1997. DOI: https:/l doi.org/10.1590/S0103-73311997000200004. Disponível em: https://www.scielo.br/scielo.php?pid=S010373311997000200004\&script=sci_abstract\&tlng=pt. Acesso em: 13 jan. 2021.

JENKINS, Henry. Convergence culture: where old and new media collide. Nova lorque: Aleph, 2006.

LÉVY, Pierre. Cibercultura. Tradução: Carlos Irineu da Costa. São Paulo: Editora 34, 2009.

LUCENA, Bianca Bulcão; SEIXAS, Cristiane Marques; FERREIRA, Francisco Romão. Ninguém é tão perfeito que não precise ser editado: fetiche e busca do corpo ideal. Psicologia USP, São Paulo, v. 31, e190113, 2020. DOI: https://doi.org/10.1590/0103-6564e190113. Disponível em: https://www.scielo.br/j/pusp/a/TT3T5xy4 qRyGmL5tFmjdYaN/?lang=pt. Acesso em: 08 jun. 2021.

MARSHALL, P. David. Celebrity and power: fame in contemporary culture. Minneapolis: University of Minnesota Press, 1997.

MARTELETO, Regina Maria. Redes sociais, mediação e apropriação de informações: situando campos, objetos e conceitos na pesquisa em Ciência da Informação. Tendências da Pesquisa Brasileira em Ciência da Informação, Brasília, DF, v. 3, n. 1, p. 27-46, jan.-dez. 2010. Disponível em: https://www.arca.fiocruz.br/ bitstream/icict/2247/1/Marteleto redes\%20sociais $\% 20$ mediacao\%20 \% 20 apropriacao\%20de\%20informacoes. pdf. Acesso em: 13 jan. 2021.

MENEZES, Maria Fátima Garcia de; PRADO, Shirley Donizete; CARVALHO, Maria Cláudia da Veiga Soares; FERREIRA, Francisco Romão. Reflexões sobre alimentação saudável para idosos na agenda pública brasileira. Revista Brasileira de Geriatria e Gerontologia, Rio de Janeiro, v. 18, n. 3, p. 599-610, 2015. DOI: https://doi.org/10.1590/1809-9823.2015.14235. Disponível em: https://www.scielo.br/scielo.php?pid=S180998232015000300599\&script=sci_abstract\&tIng=pt. Acesso em: 13 jan. 2021.

MOSCOVICI, Serge. Representações sociais: investigações em psicologia social. Petrópolis: Vozes, 2009.

PENA, Felipe. Celebridades e heróis no espetáculo da mídia. Revista Brasileira de Ciências da Comunicação, v. 25, n. 1, p. 146-157, jan.-jun. 2002. Disponível em: http://www.portcom.intercom.org.br/ revistas/index.php/revistaintercom/article/view/447/416. Acesso em: 14 jan. 2021.

PIMENTEL, Márcia Cristina. A construção da celebridade midiática. Contemporânea, Rio de Janeiro, v. 3, n. 1, p. 193-203, 2005. DOI: https://doi.org/10.12957/contemporanea.2005.17079. Disponível em: https://www.epublicacoes.uerj.br/index.php/contemporanea/article/view/17079/12564. Acesso em: 14 jan. 2021.

POLLAN, Michael. Em defesa da comida. Rio de Janeiro: Intrínseca, 2008.

PRIMO, Alex. A busca por fama na web: reputação e narcisismo na grande mídia, em blogs e no Twitter. In: CONGRESSO BRASILEIRO DE CIÊNCIAS DA COMUNICAÇÃO, 32., 4 a 7 de setembro de 2009, Curitiba, PR. Anais [...]. São Paulo: USP, 2009.

SANTAELLA, Lucia. Culturas e artes do pós-humano: da cultura das mídias à cibercultura. São Paulo: Paulus, 2003.

SCOLARI, Carlos Alberto. Narrativas transmedia: cuando todos los medios cuentan. Barcelona: Deusto, 2013. 
SCRINIS, Gyorgi. Nutricionism: the science and politics of dietary advice. New York: Columbia University Press, 2013.

SENNETT, Richard. O declínio do homem público: as tiranias da intimidade. 2. ed. Rio de Janeiro: Record, 2016.

SIBILIA, Paula. O show do eu: a intimidade como espetáculo. Rio de Janeiro: Nova Fronteira, 2008.

SILVA, Denise Oliveira e; RECINE, Elisabetta G. Iole Giovanna; QUEIROZ, Eduardo Flávio Oliveira. Concepções de profissionais de saúde da atenção básica sobre a alimentação saudável no Distrito Federal, Brasil. Cadernos de Saúde Pública, Rio de Janeiro, v. 18, n. 5, p. 1367-1377, set./out. 2002. DOI: https:/l doi.org/10.1590/S0102-311X2002000500030. Disponível em: https://www.scielo.br/scielo.php?pid=S0102311X2002000500030\&script=sci_abstract\&tIng=pt. Acesso em: 15 jan. 2021.

SILVERSTONE, Roger. Por que estudar a mídia?. São Paulo: Loyola, 2002.

SODRÉ, Muniz. Antropológica do espelho: uma teoria da comunicação linear e em rede. Petrópolis: Vozes, 2002.

STASIAK, Daiana. Sociedade midiatizada: as afetações do campo dos media na contemporaneidade.

Comunicação \& Informação, Goiânia, v. 12, n. 2, p. 75-88, jul.-dez. 2009. Disponível em: https://revistas.ufg. br/ci/article/view/12271/8133. Acesso em: 15 jan. 2021.

ZOVIN, Cristiane. Celebridades: a influência nos padrões de consumo no Brasil. Rio de Janeiro: E-papers, 2010. 